\title{
Distal renal tubular acidosis in mice that lack the forkhead transcription factor Foxi1
}

\author{
Sandra Rodrigo Blomqvist, ${ }^{1}$ Hilmar Vidarsson, ${ }^{1}$ Sharyn Fitzgerald, ${ }^{2}$ Bengt R. Johansson, ${ }^{3}$ \\ Anna Ollerstam, ${ }^{4}$ Russell Brown, ${ }^{4}$ A. Erik G. Persson, ${ }^{4}$ Göran Bergström, ${ }^{2}$ and Sven Enerbäck ${ }^{1}$
}

${ }^{1}$ Medical Genetics, Department of Medical Biochemistry, ${ }^{2}$ Department of Physiology, and ${ }^{3}$ The Electron Microscopy Unit, Institute of Anatomy and Cell Biology, Göteborg University, Göteborg, Sweden. ${ }^{4}$ Department of Medical Cell Biology, Division of Physiology, Uppsala University, Uppsala, Sweden.

\begin{abstract}
While macro- and microscopic kidney development appear to proceed normally in mice that lack Foxi1, electron microscopy reveals an altered ultrastructure of cells lining the distal nephron. Northern blot analyses, cRNA in situ hybridizations, and immunohistochemistry demonstrate a complete loss of expression of several anion transporters, proton pumps, and anion exchange proteins expressed by intercalated cells of the collecting ducts, many of which have been implicated in hereditary forms of distal renal tubular acidosis (dRTA). In Foxi1-null mutants the normal epithelium with its two major cell types - principal and intercalated cells - has been replaced by a single cell type positive for both principal and intercalated cell markers. To test the functional consequences of these alterations, Foxi1 ${ }^{-/}$mice were compared with WT littermates in their response to an acidic load. This revealed an inability to acidify the urine as well as a lowered systemic buffer capacity and overt acidosis in null mutants. Thus, Foxi1 ${ }^{-/-}$mice seem to develop dRTA due to altered cellular composition of the distal nephron epithelium, thereby denying this epithelium the proper gene expression pattern needed for maintaining adequate acid-base homeostasis.
\end{abstract}

\section{Introduction}

Some 40 mammalian forkhead genes are known today. Many of these genes play important roles during embryogenesis, for example, neuralization (Foxa2) (1), mesoderm induction (Foxf1) $(2,3)$, and kidney formation (Foxd1) (4). Foxi1 (also known as HFH3, Fkh10, or FREAC6) was first described as a kidney-expressed forkhead gene $(5,6)$. Overdier et al. (7) showed that Foxi1 expression is localized to the distal nephron in mice at embryonic day 16 (E16). At an earlier stage, E9.5, Hulander et al. (8) demonstrated an otic vesicle-specific expression. Starting at E11.5 this expression gradually becomes restricted to the endolymphatic duct/sac epithelium of the inner ear (9). Mice lacking Foxi1 are deaf and display signs of disturbed balance due to expansion of the endolymphatic compartment of the inner ear, a phenotype very similar to that which has been reported for the $\mathrm{Pds}^{-/-}$(anion transporter pendrin) mouse $(9,10)$. Foxi1 $1^{-/}$mice lack Pds expression in the endolymphatic inner ear epithelium, thus establishing Foxi1 as an upstream regulator of $P d s$ at this location (9).

Guided by the facts that Foxi1 and Pds also are expressed in the kidney $(8,11)$ and that $\mathrm{Pds}^{-/-}$kidney tubuli exhibit a defect bicarbonate secretion in vitro that might contribute to a mild form of alkalosis (although neither Pendred syndrome patients nor pendrin-deficient mice develop any overt acid-base disturbance; ref. 12), we set out to examine a possible role for Foxi1 as a regulator of adult kidney function. Our initial hypothesis was one in which a similar and possibly more aggravated kidney disturbance was to be expected in adult kidneys lacking Foxi1 as compared with those with no pendrin expression, assuming a role for Foxi1 as a regu-

Nonstandard abbreviations used: anion exchange protein 1 (AE1); aquaporin 2 (AQP2); carbanhydrase II (CAII); cortical collecting duct (CCD); distal renal tubular acidosis (dRTA); embryonic day (E); $\mathrm{K}^{+} / \mathrm{Cl}^{-}$cotransporter 4 (Kcc4); kidney isoform of AE1 (kAE1); nucleotide (nt); pendrin (Pds); transmission electron microscopy (TEM) Conflict of interest: The authors have declared that no conflict of interest exists.

Citation for this article: J. Clin. Invest. 113:1560-1570 (2004).

doi:10.1172/JCI200420665. lator of Pds expression in the kidney similar to that of the inner ear. To our surprise we found that Foxi1//- mice produce urine with elevated $\mathrm{pH}$ compared with WT mice, the opposite of what one would expect based on the finding of a reduced capacity of $\mathrm{Pds}^{-/}$kidney tubuli to secrete bicarbonate in vitro (12). To resolve this we analyzed expression levels of potential Foxi1 target genes emphasizing those that, when mutated, are known to cause distal renal tubular acidosis (dRTA).

Northern blot and immunohistochemistry experiments fail to identify any expression of either AE1 (anion exchange protein 1 ), implicated in some forms of dRTA (13), or pendrin in $\alpha$ - and $\beta$-intercalated cells, respectively (14). Expression levels of ATP6B1 mRNA (encoding the $\mathrm{B}_{1}$ subtype of $\mathrm{H}^{+}$ATPase), also linked to dRTA (15), were normal, while no immunoreactive protein could be identified in Foxi1-/- kidneys. $\mathrm{Kcc} 4\left(\mathrm{~K}^{+} / \mathrm{Cl}^{-}\right.$cotransporter 4$)$ associated with other forms of renal tubular acidosis (16) remain unaffected. We could also demonstrate a complete absence of AE4, in epithelium lacking Foxi1. AE4 is normally expressed in intercalated cells $(17,18)$. Furthermore, in Foxi1 $1^{-/-}$mice kidney formation appears to proceed properly, producing a morphologically normal metanephric kidney as judged by macroscopic appearance and light microscopy (8). Using transmission electron microscopy (TEM), we could identify altered cellular morphology in the epithelium of the distal nephron. Since intercalated cells of the distal nephron are specialized for physiologically regulated proton transport and express AE1 (19), AE4 (18), Pds (12), ATP6B1 (19), and Kcc4 (16), we examined the capacity of Foxi1-/- mice to secrete protons in response to both a chronic as well as an acute acidic load. In comparison with WT littermates, the null mutants are significantly hampered in these capacities; they also consume significantly more of their systemic buffering capacity. Subjected to a more prolonged acidic load Foxi 1//- mice develop overt acidosis. Taken together, these experiments point toward an important role for Foxi1 in regulating the proton-secreting capacity of collecting duct epithelium. Thus, Foxi1 expression appears to be a 
prerequisite for normal function of intercalated cells in the mature kidney. In an attempt to analyze the cellular composition of the distal nephron epithelium in Foxi1 1 - mice, we used Ab's against CAII (carbanhydrase II), a marker for intercalated cells $(20,21)$, and AQP2 (aquaporin 2), a marker for principal cells $(22,23)$. In WT epithelium we can identify subsets of cells positive for either marker, whereas in Foxi1 ${ }^{-/}$kidneys the entire epithelium appears to consist of a single cell type positive for both markers. This points toward a role for Foxi1 as a factor necessary for correct patterning of distal nephron epithelium. As a consequence, genes necessary for proper acid-base handling fail to be induced in null mutants.

The division of intercalated cells into two major groups of $\alpha$-and $\beta$-intercalated cells, based on the intracellular localization of the proton pump and other features, clearly is an oversimplification. The epithelia of the distal segments of the nephron, including connecting tubule and collecting ducts, is highly heterogeneous. Intercalated cells make up approximately $40 \%$ of the epithelium in the distal nephron (14). They can be divided into at least two, possibly three, distinct cell types, $\alpha$ - and $\beta$-intercalated cells, as well as non- $\alpha$-non- $\beta$-intercalated cells $(24,25)$. The exact functional role of non- $\alpha$-non- $\beta$ intercalated cells is unclear. While some argue for a close relation to $\beta$-intercalated cells, others endow these cells with unique features (26-28). Other investigators have proposed an interesting hypothesis, suggesting a high degree of plasticity in terms of intercalated cell phenotypes (29). According to this idea, intercalated cells can undergo "adaptive conversion" in response to external cues, that is, interchange between an $\alpha$ - and $\beta$-phenotype $(29,30)$. In this way intercalated cells can exist in a continuum of subtypes. Here we use the terms $\alpha$ - and $\beta$-intercalated cells with the understanding that $\alpha$-intercalated cells are thought to be involved in proton secretion and present in both medulla and cortical collecting tubuli, while $\beta$-intercalated cells take part in bicarbonate secretion and are found mainly in cortical collecting tubuli (14).

\section{Methods}

TEM. Slices of kidneys were fixed for electron microscopy by immersion in $2 \%$ paraformaldehyde $/ 2.5 \%$ glutaraldehyde $/ 0.01 \% \mathrm{Na}$ azide in $0.05 \mathrm{M} \mathrm{Na}$ cacodylate buffer, $\mathrm{pH}$ 7.2. Samples of cortex were further treated with $1 \% \mathrm{OsO}_{4} / 1 \%$ potassium ferrocyanide in $0.1 \mathrm{M}$ cacodylate followed by en bloc staining with uranyl acetate. Specimens were dehydrated and embedded in epoxy resin according to routine procedures. Ultrathin sections $(\sim 60 \mathrm{~nm})$ were obtained with a Reichert Ultracut E ultrotome (Leica Microsystems, Vienna, Austria) fitted with a diamond knife. They were contrasted with uranyl acetate and lead citrate before examination in a LEO 912AB TEM (LEO Electron Microscopy Group, Oberkochen, Germany). Digital images were captured with a side-mounted MegaView III CCD camera (Soft Imaging System GmbH, Münster, Germany).

Northern blot analysis. Twenty micrograms of total RNA, prepared as previously described (31), from WT and Foxi1-/- kidneys were electrophoresed on a $2 \%$ formaldehyde/ $1 \%$ agarose gel and transferred to Gene Screen Plus membrane (PerkinElmer Life Science Inc., Boston, Massachusetts, USA). The membranes were hybridized with the following ${ }^{32}$ P-labeled cDNA probes: 483-bp Foxi1 fragment (corresponding to nucleotide [nt] 1185-1667 in GenBank entry 24475696 at www.ncbi.nlm.nih.gov), a 617-bp AE1 fragment (corresponding to nt 3685-4301 of IMAGE clone 440301), a 1,697-bp Pds fragment (corresponding to nt 948-2644 of GenBank entry 6755021), a 200-bp ATP6B1 fragment (corresponding to nt 14271626 of IMAGE clone 6444350), and a 214-bp Kcc4 fragment (cor- responding to nt 361-574 of GenBank entry 5051639). The probes were cloned by PCR (Invitrogen SuperScript First-Strand Synthesis System for RT-PCR, 11904-018; Invitrogen Life Technologies, Paisley, United Kingdom), and cDNA was ligated into pBluescript. The probes were sequence verified on a ABI 310 sequencing instrument. For hybridizations, QuickHyb (Stratagene, La Jolla, California, USA) was used according to product protocol. Hybridization temperatures were in the $62-65^{\circ} \mathrm{C}$ range. As an internal standard a $\beta$-actin cDNA probe was used.

Tissue culture and transfections. The entire coding region of FOXI1 was cloned into the expression vector pcDNA3.1. The AE1-luciferase reporter construct was cloned by PCR amplification of a 906-bp fragment (corresponding to nt 6758-7663, GenBank entry 598145) from the kidney AE1 promoter (32) ligated into a pGL3-Basic vector (Promega Corp., Madison, Wisconsin, USA). The Pds-luciferase promoter construct was made from a 5,010-bp upstream fragment (corresponding to nt 32478972-32483981, GenBank entry 29798863) cloned into a pGL3-Basic vector. All constructs were sequence verified. COS-7 cells were cultured in DMEM (Life Technologies Inc., Gaithersburg, Maryland, USA) supplemented with $10 \%$ (vol/vol) FCS, $100 \mathrm{U} / \mathrm{ml}$ penicillin, and $100 \mu \mathrm{g} / \mathrm{ml}$ streptomycin (Life Technologies Inc.). Cells were grown on 24 -well plates to $50-80 \%$ confluence before transfection. Transient transfections were performed with Lipofectamine (Invitrogen Life Technologies), using $110 \mathrm{ng}$ of luciferase reporter plasmid and 20-40 ng of cotransfected expression vector in accordance with the manufacturer's protocol. Differences in transfection efficiencies were assayed by cotransfecting each well with $10 \mathrm{ng}$ of CMV-Renilla reporter (Promega Corp.). Luciferase activities were determined as fold induction of relative cells transfected with an expression vector, void of insert, and normalized to Renilla activity. Experiments were performed in triplicate.

In situ bybridization. Nonradioactive in situ hybridization of adult mouse kidney cryosections $(10 \mu \mathrm{m})$ were carried out as described
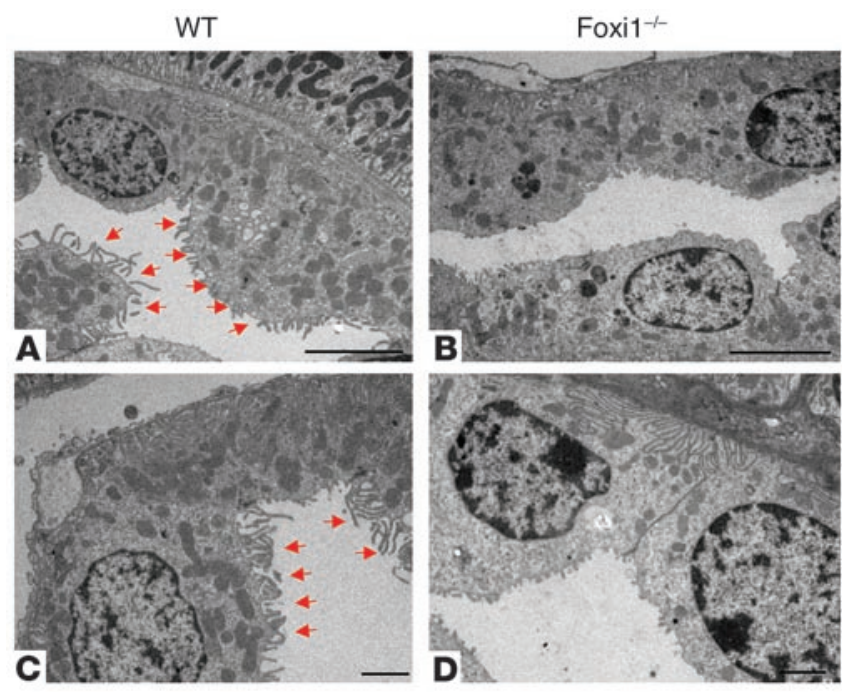

Figure 1

TEM of kidney CCD cells in WT (A and $\mathbf{C})$ and Foxi1 ${ }^{--}(\mathbf{B}$ and $\mathbf{D})$ mice. Red arrows mark cells with a protruding "tussock-like" apex that are rich in mitochondria (A and $\mathbf{C}$ ). Cells with this appearance are missing from CCD of Foxi1 ${ }^{-1-}$ origin (B and D). Scale bars: $\mathbf{A}$ and B, $5 \mu \mathrm{m} ; \mathbf{C}$ and $\mathbf{D}, 2 \mu \mathrm{m}$. 

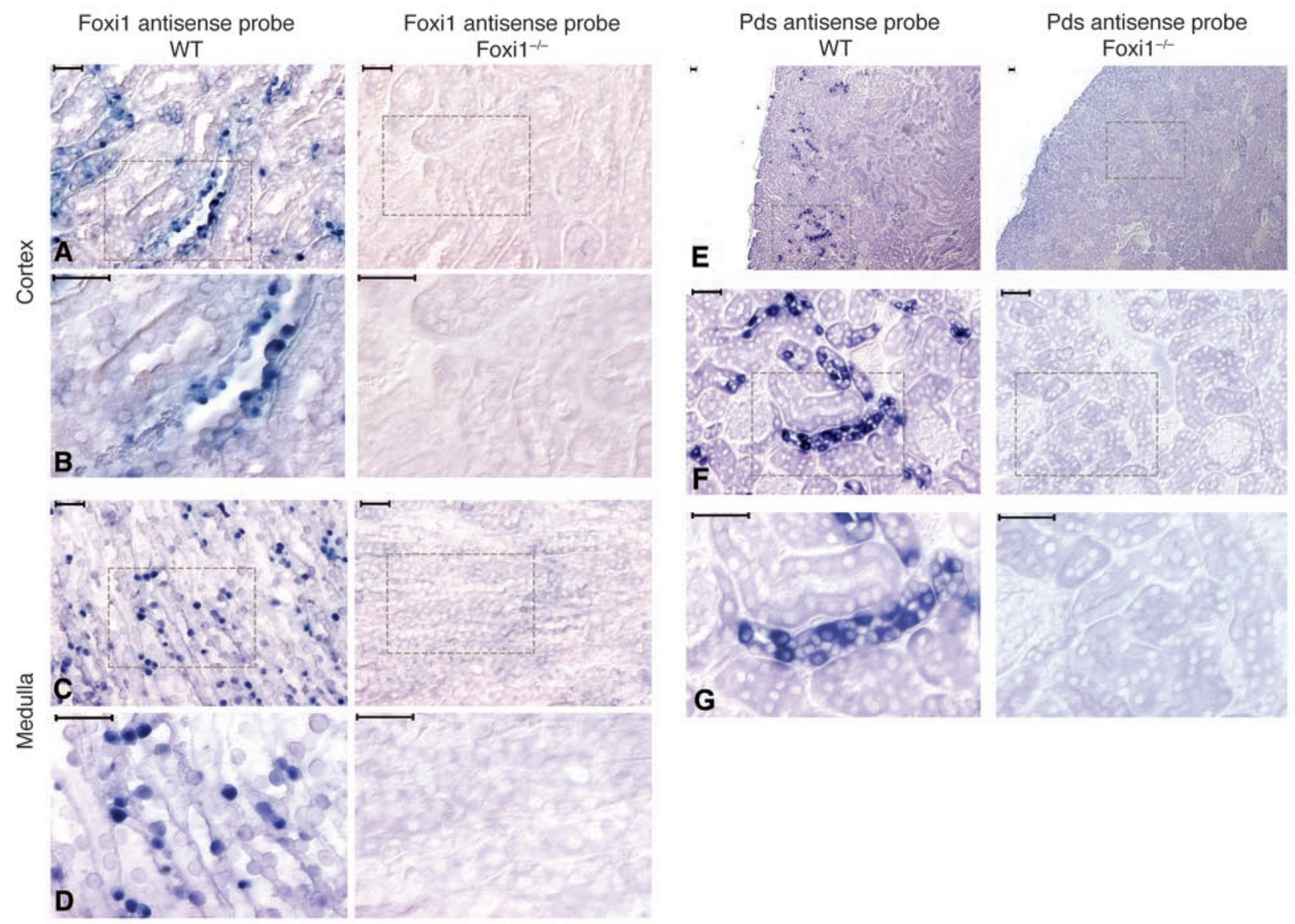

\section{Figure 2}

The cRNA in situ hybridization of mouse kidney sections of WT and Foxi1 ${ }^{-/}$origin using antisense probes for Foxi1 (A-D) and Pds (E-G). In cortical sections, Foxi1-positive cells are localized to tubular regions (A). At higher magnification, a scattered pattern of hybridization signals is clearly visualized. While some cells are densely stained, others remain unstained (B). In medulla sections, cells positive for Foxi1 are scattered and distributed along the collecting ducts (C). At a higher magnification, it is evident that some cells stain and others lack any clear hybridization signal (D). The antisense Pds cRNA probe identifies a pattern of scattered tubular cells in cortical sections (E-G). No signals from cells in the medulla can be identified (E). At higher magnification, it is clear that some cells stain, while others do not ( $\mathbf{F}$ and $\mathbf{G})$, a pattern very similar to that for Foxi1 in the cortex (A and B). No Pds signals can be identified in Foxi1-1- kidneys. Scale bars: $40 \mu \mathrm{m}$.

previously (33), except that hybridization temperatures were set to $68^{\circ} \mathrm{C}$ for the Pds cDNA probe (corresponding to nt $948-2645$ of GenBank entry 6755021 ) and $70^{\circ} \mathrm{C}$ for the Foxi $1 \mathrm{cDNA}$ probe (corresponding to nt 966-1668 of GenBank entry 24475696). Combined cRNA and immunohistochemistry in situ analysis was performed as described previously (34).

Immunohistochemistry. Cryosections $(10 \mu \mathrm{m})$ were fixed in ice-cold methanol for 20 minutes, pressure boiled in antigen-retrieval buffer (40 mM Tris-Cl, 0.1 mM EDTA, pH 8) for 10 minutes, and blocked in $1 \% \mathrm{BSA} / 0.5 \%$ Triton- $\mathrm{X}$ in $1 \times$ PBS. Primary Ab's, rabbit polyclonal anti-pendrin, h766-780 (12), 1:100; rabbit anti-rat AE1, 1:100 (AE11-A; Alpha Diagnostics International Inc., San Antonio, Texas, USA); rabbit anti-human AE4, 1:100 (AE41-A, Alpha Diagnostics International Inc.); rabbit anti-human AQP2 (35), 1:800; rabbit anti-CAII, 1:200; rabbit anti-Kcc4, 1:50; rabbit $\mathrm{H}^{+}$-ATPase against the $\mathrm{B} 1$ subunit, $1: 100$, were diluted in $0.2 \% \mathrm{BSA} / 0.1 \%$ Triton-X and incubated overnight at $4^{\circ} \mathrm{C}$. Following five 10 -minute washes in $1 \times$ PBS the sections were incubated 1 hour in diluted secondary $\mathrm{Ab}$ (1:50-1:500), Alexa Fluor 568-conjugated goat anti-rabbit IgG (A11011; Molecular Probes Inc., Eugene, Oregon, USA). Nuclei were visualized using ToPro3, 1:1,000 (T3605; Molecular Probes Inc.). The sections were mounted in ProLong Antifade (P7481; Molecular Probes Inc.) and imaged with a Zeiss LSM 510 META confocal microscope. For sections stained with more than one antiserum, we used the Zenon system according to the manufacturer's protocol (rabbit IgG labeling kit, Z25360; Molecular Probes Inc.).

Morphometric analysis. The number of AQP2-positive tubuli cells in the cortex and outer and inner medulla was counted. In a view field at a magnification of $\times 400$, the total number of cells in the AQP2-stained tubules were counted using the nuclear stain ToPro3 (T3605; Molecular Probes Inc.). The number of CAII-positive cells, followed by the number of AQP2-positive cells, and finally the number of cells that stained positive for both CAII and AQP2 were counted. The cells in at least 25 tubuli of the cortex and 40 tubuli in both outer and inner medulla were counted (corresponding to $300-500$ cells/kidney region) for each animal. Three WT and three Foxi1 ${ }^{-/}$kidneys from separate animals were used. Average values spread less than plus or minus $15 \%$.

Urine and serum analysis. To measure electrolyte levels and kidney excretion of electrolytes we used mice with a weight of 20-25 g. Anes- 

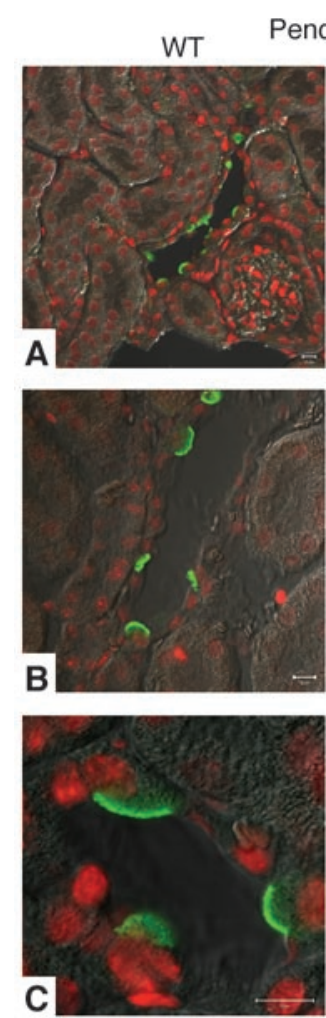

Foxi1 ${ }^{-1-}$
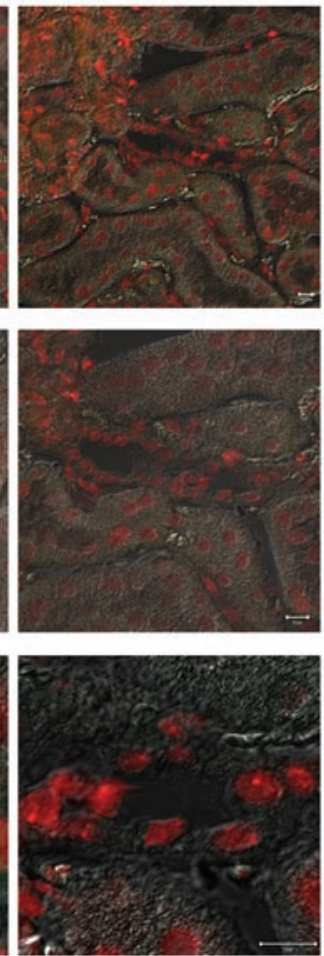

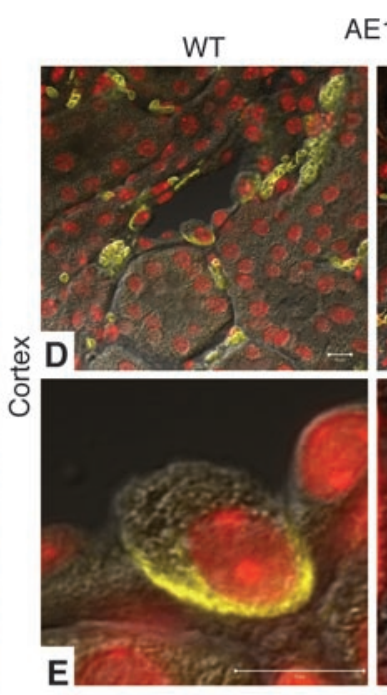

AE1
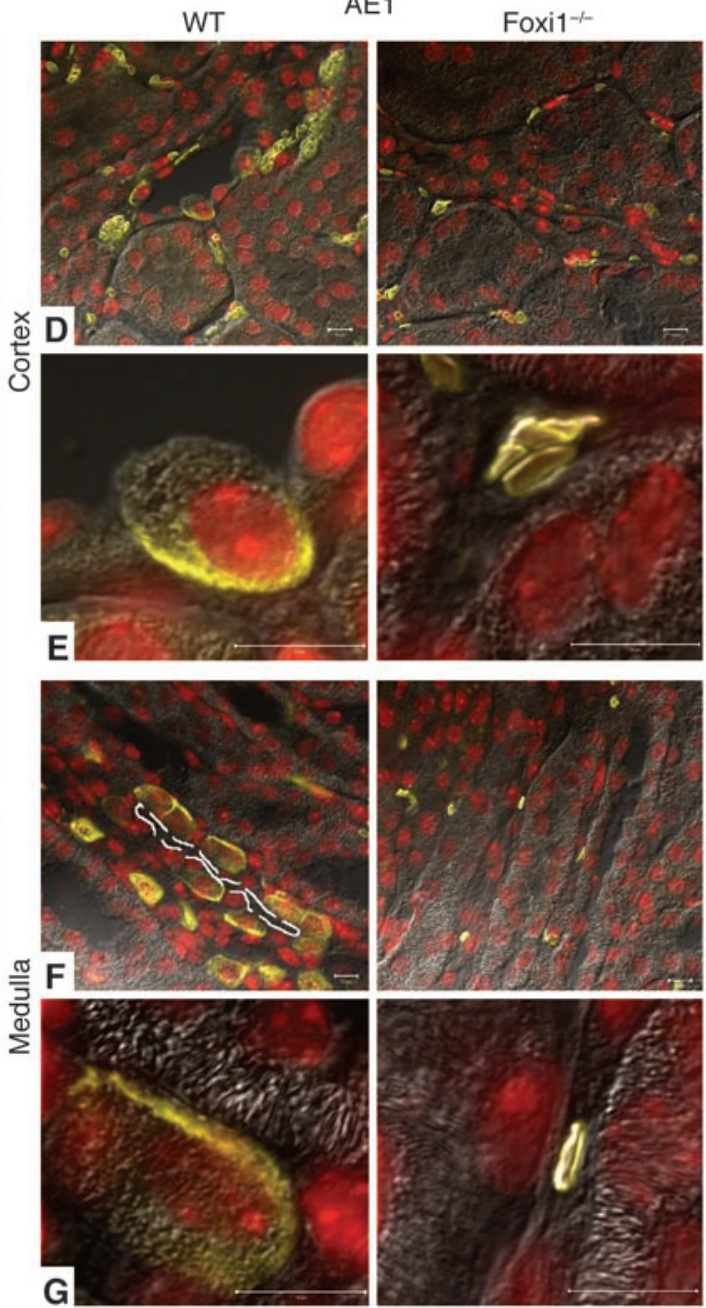
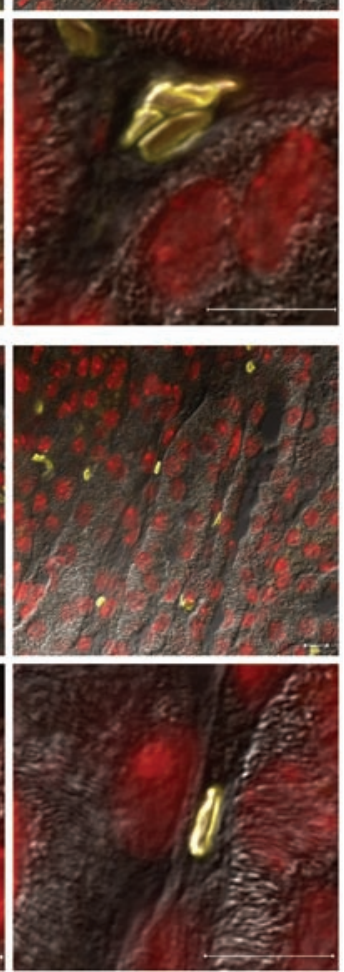

\section{Figure 3}

Confocal images of cortical sections using Ab's against Pds (green) (A-C), AE1 (yellow) (D-G) as well as ToPro3 for nuclear staining (red). In WT kidneys, an api$\mathrm{cal} /$ luminal staining pattern is visualized, which agrees well with previous observations (12). Apical Pds signals mark $\beta$-intercalated cells (12). In Foxi1-/- sections, no Pds signal can be detected. In the cortex of WT mice, tubular cells are AE1 positive (D), mostly at their basolateral border (E). In the medulla, a similar pattern is visualized (F and $\mathbf{G})$. The lumen is marked with a dashed white line in $\mathbf{F}$. In Foxi1-/- kidneys, no parenchymal staining can be identified; only erythrocytes stain ( $\mathbf{D}$ and $\mathbf{E}$ ), since the antiserum (apart from identifying the kidney and $\alpha$-intercalated cell-specific isoform of $A E 1$ ) also recognizes the erythrocyte isoform of $A E 1$ (41). Scale bars: $10 \mu \mathrm{m}$. thesia was induced by spontaneous inhalation of isoflorane (Forene; Abbot Laboratories, Abbott Park, Illinois, USA.) The inhalation gas was a mixture of $40 \%$ oxygen and $60 \%$ nitrogen, containing approximately 2.2\% isoflorane. Mice were placed on a servoregulated heating pad to maintain body temperature at $37.5^{\circ} \mathrm{C}$. A catheter was inserted into the left jugular vein for infusion of maintenance fluid $(0.9 \%$ $\mathrm{NaCl}$ and $2 \%$ albumin, $0.35 \mathrm{ml} / \mathrm{h}$ ). Total kidney urine flow rate was determined from samples taken through a catheter in the urinary bladder. After the surgical procedure, the animals were allowed to stabilize for 45 minutes, followed by a 40-minute sampling period. Urinary and plasma electrolyte concentrations were determined by flame photometry (FLM3; Radiometer, Copenhagen, Denmark).

Mice and acid-base measurements. Foxi1 $1^{-/-}$mice on a CD1 and $\mathrm{Pds}^{-/-}$ mice on Bl6 background were used (backcrossed for at least five generations), and they were always compared with WT littermates. For the chronic acidic load, 4-month-old WT $(n=5)$ and Foxi1-/$(n=5)$ mice were fed a standard chow (R34; Lactamin AB, Stockholm, Sweden). When dissolved in water, the chow releases $70 \mu \mathrm{mol}$ titratable $\left[\mathrm{H}^{+}\right]$per gram of chow. Hence, the chow used constitutes a moderate acidic load. Urine for $\mathrm{pH}$ analysis was collected in specially designed mouse urine collection cages, and $\mathrm{pH}$ was measured in 24-hour aliquots. For acute acidic load 4-month-old WT $(n=4)$ and Foxi1 ${ }^{-/-}(n=4)$ mice were subjected to an acute acidic load, essentially as has previously been described (36). In short, vehicle (distilled water, $3 \%$ of body weight) was administered through a gastric tube, and after 7 days of recovery, the same set of animals were in the same way administered $\mathrm{NH}_{4} \mathrm{Cl}(0.8 \mathrm{~g} / \mathrm{kg}$ body weight with $3 \%$ body weight of distilled water). They were kept individually in metabolic cages for 24 hours with access to water and chow. Urine was collected 4 hours after the mice were given vehicle or $\mathrm{NH}_{4} \mathrm{Cl}$. The difference in urine $\mathrm{pH}$ in response to vehicle and $\mathrm{NH}_{4} \mathrm{Cl}$ administration was calculated. Twenty-four hours after $\mathrm{NH}_{4} \mathrm{Cl}$ administration, blood was drawn from the tail vein for evaluation of the acid-base status. For chronic $\mathrm{NH}_{4} \mathrm{Cl}$ acidic load, 4-month-old WT $(n=5)$ and Foxi1 ${ }^{-/-}(n=5)$ were subjected to a chronic acidic load, essentially as previously described (37). In brief, mice were given $2 \%$ sucrose $/ 0.28 \mathrm{~mol} / \mathrm{I} \mathrm{NH}_{4} \mathrm{Cl}$ in the drinking water for 7 days. They were kept in standard cages between days 1 and 6, but moved to metabolic cages the last night. Blood was drawn from the tail vein and analyzed for acid-base status. Acid-base status was determined in a Radiometer ABL 725 acid-base analyzer (Radiometer). Standard bicarbonate levels were determined from whole blood equilibrated at $40 \mathrm{~mm} \mathrm{pCO}_{2}$ and oxygen-saturated hemoglobin at $37^{\circ} \mathrm{C}$. All animal experiments were approved by the ethical committees at Göteborg University and Uppsala University.

Statistics. All values are given as mean plus or minus SEM. Student's $t$ test was used for statistical analysis. A $P$ value less than 0.05 was considered to be significant. 


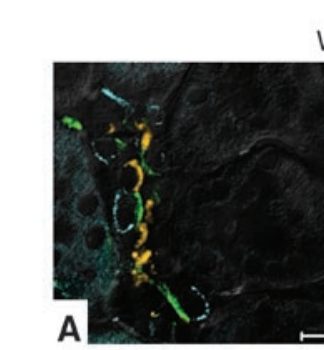

WT
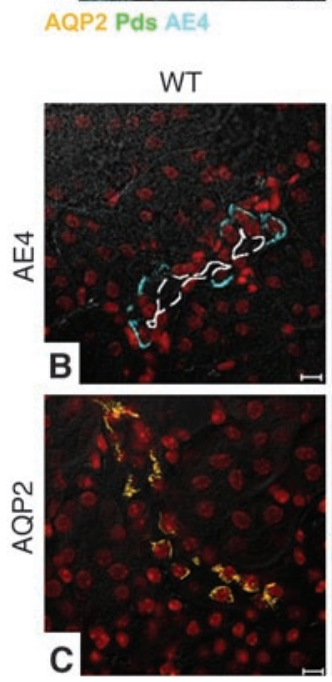
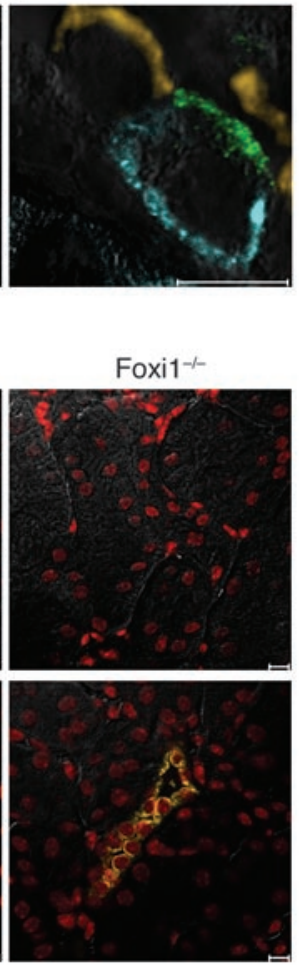

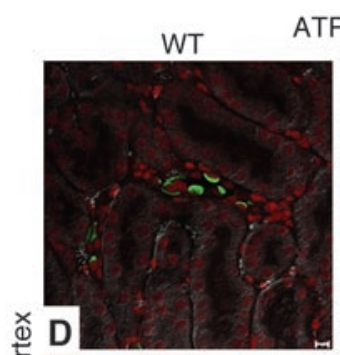

ঠั
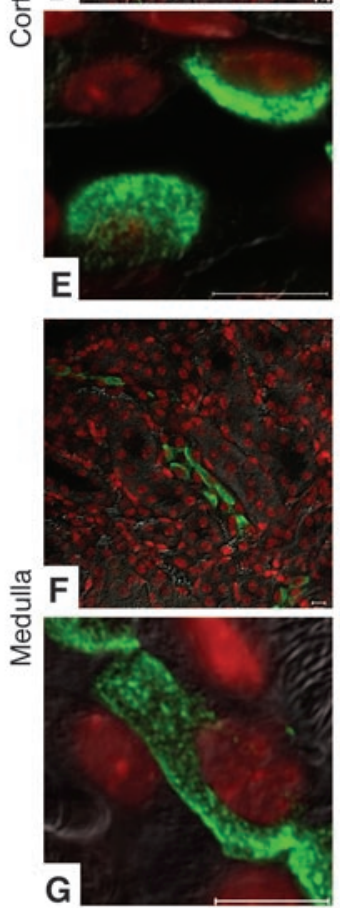

ATP6B1
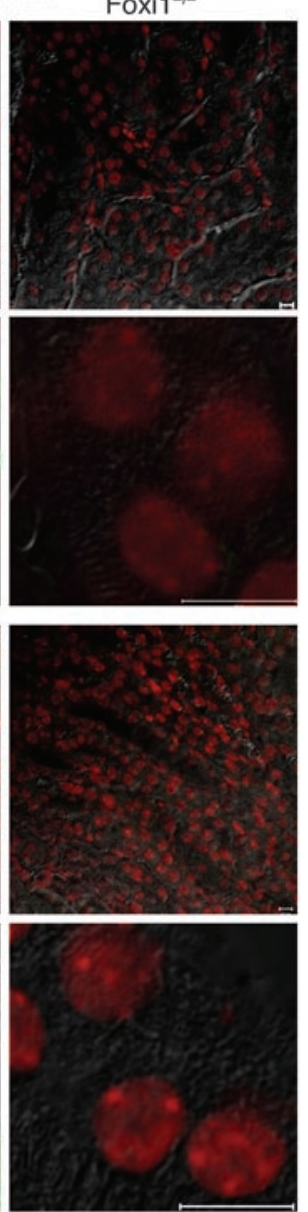

Figure 4

In confocal images of WT kidney sections, $\beta$-intercalated cells stain positive for $\mathrm{Pds}$ (green) and AE4 (blue) at their apical and basolateral border, respectively. Principal cells stain positive for AQP2 (orange) at their apical aspect (A). While AE4 staining is absent in Foxi1 $1^{-/-}$kidneys (B) (lumen marked with a dashed white line), AQP2 signals are present in both WT and Foxi1 ${ }^{-/}$sections (C). AQP2 appears to stain a high fraction of epithelial cells in Foxi1-/- sections (right panel), as compared with WT (left panel) (C). ATP6B1 is absent from distal nephron epithelia in Foxi1 ${ }^{-/-}$mice both in cortex (right panels) (D and $\mathbf{E}$ ) and medulla (right panels) ( $\mathbf{F}$ and $\mathbf{G}$ ), as compared with WT (left panels) (D-G). Scale bars: $10 \mu \mathrm{m}$.

\section{Results}

Altered ultrastructure of distal nephron epithelia in Foxi1-null mutant mice. Since earlier studies had shown that Foxi1 is expressed in the distal part of the nephron (7), we set out to study morphology of kidneys lacking Foxi1 expression. Despite careful monitoring of kidney morphology during embryogenesis as well as in adult mice, no difference between WT and Foxi1/-/ kidneys could be detected using light microscopy (not shown). With the aid of TEM, however, we could demonstrate an altered ultrastructure of cortical collecting duct (CCD) epithelia; a cell type found in WT epithelia appears to be missing in null mutants (Figure 1). This tussock-like, mitochondria-rich cell type with a protruding microvillous apex shares several characteristics with what has been described for $\alpha$-intercalated cells (38). Thus, this experiment demonstrates an altered cellular morphology of the CCD epithelium in Foxi1-/- mice, possibly due to lack or altered structure of intercalated cells (Figure 1).

Pendrin is not expressed in Foxi1 ${ }^{-1-}$ kidneys. We used cRNA in situ hybridizations to localize kidney cells expressing Foxi1. In cortical sections Foxi1 is expressed in a punctuated pattern in epithelia of distal nephrons (Figure 2, A and B). In medulla sections Foxi1positive cells are scattered along the epithelia of collecting ducts (Figure 2, C and D). We performed in situ hybridizations using a Pds cRNA probe to examine whether kidneys lacking Foxi1 still express Pds (Figure 2, E-G) or if the situation is analogous to that of the endolymphatic duct/sac epithelium where Foxi1 is a pre- requisite for Pds expression (9). While no signal can be detected in Foxi $1^{-/-}$kidneys the expected hybridization pattern was found in WT mice with staining of predominantly $\beta$-intercalated cells in the cortical part of the distal nephron $(12,39)$. Using a Pds-specific antiserum, we were able to localize Pds to the apical/luminal part of WT cells, whereas Foxi1/- kidneys seem to lack immunoreactive Pds (Figure 3, A-C). We also made whole-kidney preparations of RNA, and Northern blot analyses confirm these results: no signal can be detected in $\mathrm{Foxi}^{-/-}$RNA preparations, while $\beta$-actin can be readily visualized to approximately the same extent in both WT and Foxi1 $1^{-/}$preparations (Figure 5A). The fact that Foxi1 is expressed in tubular cells of the cortex similar to Pds (Figure 2, A, B, E-F) supports the role of Foxi1 as a regulator of Pds expression in the $\beta$-intercalated cells of the kidney tubuli. Foxi1 is also expressed in the medulla (Figure 2, C and D), where we find no Pds expression (Figure 2E).

AE1, AE4, and ATP6B1 are missing, while AQP2 is expressed in collecting duct epithelia of mice that lack Foxi1. To further study potential target genes regulated, indirectly or directly, by Foxi1, we examined the expression level of AE1, known to be expressed in $\alpha$-intercalated cells (40). Mutations in this gene have been shown to cause a dominant autosomal form of dRTA (13), which is triggered by an inability to acidify the urine. Immunohistochemistry using an AE1-specific antiserum reveals a basolateral staining pattern as expected in WT kidneys; in Foxi1-/- kidneys we see no such staining (Figure 3, 
$D-G)$. Since the antiserum is directed against the $C$ terminus of AE1 and an alternatively spliced product of the $\mathrm{AE} 1$ gene gives rise to an isoform expressed in erythrocytes (eAE1) having identical C terminus as compared with the kidney isoform (kAE1; ref. 41), it will detect both isoforms. We did not find any extraerythrocyte staining in Foxi1//- kidneys (Figure 3, D-G), however. To confirm that AE1 is truly absent from the kidney parenchyma we used whole-kidney RNA preparations from WT and Foxi1-/- kidneys in a Northern blot assay. We found AE1 transcripts to be absent from Foxi1/- kidneys (Figure 5A). Another candidate for dRTA is the ATP6B1 gene. Mutations in this gene are responsible for an autosomal recessive form of dRTA (15). As can be deduced from Northern blot experiments (Figure 5A), no change in ATP6B1 mRNA levels can be detected when WT and Foxi1-/- kidneys are compared. When using an ATP6B1-specific antiserum, however, we fail to identify any ATP6B1 immunoreactive protein in Foxi1-/- kidneys (Figure 4, D-G). While the type of intercalated cell that expresses AE4 and the intracellular localization of this gene product is debated (17, 18 ), we show in a triple-labeling experiment of WT distal nephron epithelium using Ab's against AE4, Pds (marks $\beta$-intercalated cells; ref. 12), and AQP2 (marks principal cells; ref. 22, 23), that AE4 signals are derived from the basolateral aspect of cells that in its apical region stain for Pds, that is, $\beta$-intercalated cells. AQP2 signals are derived from the apical region of principal cells (Figure 4A). AE4 is absent in Foxi1-/- collecting duct eipthelium (Figure 4B). $\mathrm{Kcc} 4$ is expressed in many nephron segments, including $\alpha$-intercalated cells and in Corti's organ of the inner ear (16). Mice lacking $\mathrm{Kcc} 4$ are deaf and have renal tubular acidosis (16). In Foxi1 ${ }^{-/-}$mice Kcc4 mRNA expression appears to be unaffected (Figure 5A), and immunohistochemistry reveals no difference in expression pattern

A
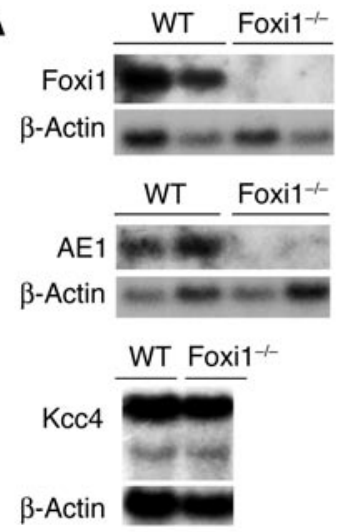

B

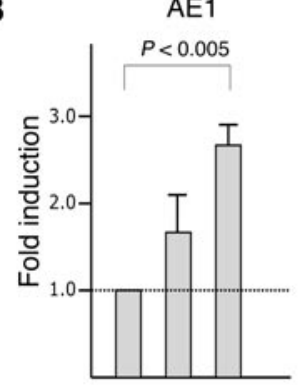

$020 \quad 40$

Foxi1 expression vector (ng)
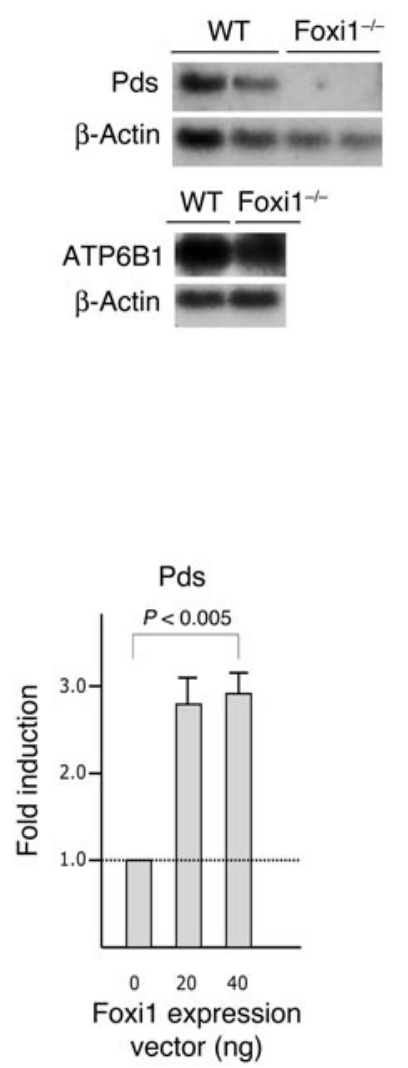

between Foxi1-/- and WT kidneys (not shown). AQP2, a marker for principal cells $(22,23)$, is expressed in a very similar pattern in both WT and Foxi1/-- kidneys (Figure 4C), with the exception that we were rarely able to identify any AQP2-negative cells in cortical collecting ducts of Foxi1 ${ }^{-/}$mice (Figure 4C, right panel).

Foxi1 is coexpressed with and transactivates Pds and AE1. Since AE1 is expressed in $\alpha$-intercalated cells and Pds in $\beta$-intercalated cells $(14,40)$, we became interested in the cellular localization of Foxi1 expression in the kidney. On WT kidney sections Foxi1 and Pds display similar cortical expression patterns (Figure 2), compatible with the view that Foxi1, indeed, is expressed in $\beta$-intercalated cells. Using specific antisera against Pds (green; Figure 6A) and AE1 (red; Figure 6A), we can demonstrate an apical/luminal staining for Pds (green) and a basolateral signal for AE1 (red) derived from $\beta$ - and $\alpha$-intercalated cells, respectively. To further examine this we performed cRNA in situ hybridization using a Foxi1 probe (Figure 6, B and C, left panels), similar to that shown in Figure 2, $A$ and D. We then stained such sections using a Pds-specific (Figure $6 \mathrm{~B}$, right panel) or AE1-specific antiserum (Figure 6C, right panel), respectively. While some of the cells positive for Foxi1 (blue and red arrows) also have apical staining for Pds (green; Figure 6B, right panel, marked with red arrows) other such cells appear not to express Pds (blue arrows). Conversely, some Foxi1-positive cells stain positive for AE1 (yellow; Figure 6C, right panel, marked with red arrow) while other such cells are negative (blue arrows). This, taken together with the fact that Foxi $1^{-/-}$kidneys do not express Pds nor AE1 (Figures 2, E-G, Figure 3, and Figure 5A), support the view that Foxi1 is expressed in the same cell types as Pds and AE1, that is, $\alpha$ - and $\beta$-intercalated cells (12). These data demonstrate that Foxi1 is expressed in both $\alpha$ - and $\beta$-intercalated cells.

The lack of AE1 and Pds transcripts in Foxi1//- kidneys made us interested in Foxi1 as a potential transactivator of AE1 and Pds promoters. To study this we set up a transfection assay in which $0.9 \mathrm{~kb}$ of $\mathrm{AE} 1$ and $5 \mathrm{~kb}$ of Pds upstream sequences were fused to a luciferase reporter gene (see Methods). As can be deduced from Figure 5B, both AE1 and Pds constructs were significantly activated by a Foxi1 expression vector as compared with an expression vector void of insert $(P<0.005)$. Both AE1 and Pds upstream sequences contain several putative forkhead-binding sites (not shown) conforming to proposed consensus sequences RYMAAYA $(\mathrm{R}=\mathrm{A}$ or $\mathrm{G} ; \mathrm{Y}=\mathrm{C}$ or $\mathrm{T} ; \mathrm{M}=\mathrm{A}$ or $\mathrm{C})(6,42)$.

Foxi1 is not expressed in AQP2-positive cells. Apart from intercalated cells, the distal nephron epithelium also consists of principal cells. This cell type is involved in sodium, potassium, and water transport (14). These cells express the water channel protein AQP2,

\section{Figure 5}

Transcript levels and transcriptional regulation in WT and Foxi1-1-. Northern blot analysis of whole-kidney RNA preparations derived from either WT or Foxi1-/- kidneys (A). While Foxi1, Pds, and AE1 signals are absent in kidney RNA prepared from Foxi1-/- mice, the same levels of ATP6B1 and Kcc4 signals are present in WT and Foxi1-/- RNA preparations. At least three independent animals (for each genotype) were examined for each probe in three independent experiments, with representative results shown. Results shown in A represent RNA from different mice. Transfection assays (B), promoter reporter gene constructs for $A E 1$, and Pds, were transfected to COS-7 cells, together with an FOXI1 expression vector (20 and $40 \mathrm{ng}$ ) with or without insert. Reporter gene activity is shown as fold induction relative to an expression vector void of FOXI1 insert. 

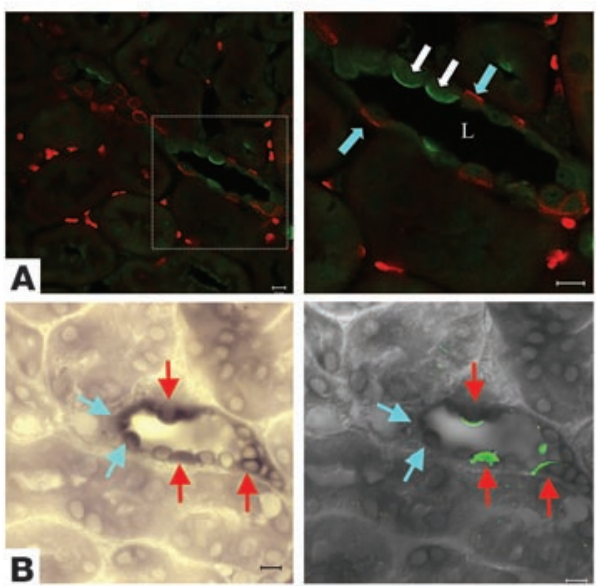

B
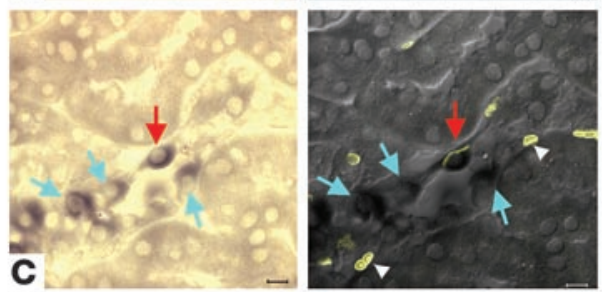

\section{Figure 6}

Distribution and identity of Foxi1 positive cells. Confocal images of cortical tubules (A). Left image is an overview, right image is a close up of a typical tubule, lumen (L). Pds (green) stains the apical region of $\beta$-intercalated cells (white arrows); AE1 (red) stains the basolateral region of $\alpha$-intercalated cells (blue arrows). Due to presence of overlapping specificity, erythrocytes stain red in a scattered pattern (see below). (B) In the left image, a Foxi1-specific cRNA probe stains tubular cells dark blue, marked with blue and red arrows. The right image shows a confocal image of the left panel using a Pds-specific $\mathrm{Ab}$ for immunohistochemistry. While apical/luminal regions of some tubular cells are Foxi1 positive and also stain positive for Pds (red arrows), other such cells are negative for Pds (blue arrows). (C) In the left image, a Foxi1-specific cRNA probe stains tubular cells dark blue (marked with blue and red arrows). The right image shows a confocal image of the left panel using a AE1-specific Ab for immunohistochemistry. While the basolateral region of a tubular cell that is Foxi1 positive also stains positive for AE1 (red arrow), other such cells are negative for AE1 (blue arrows). In right panel of $\mathbf{C}$, several erythrocytes stain (clusters marked with white arrowheads), since the antiserum used (apart from detecting the kidney isoform of $A E 1)$ also identifies the erythrocyte isoform of $A E 1$ (see corresponding section in Results). Foxi1 cRNA probes were used to identify Foxi1-positive cells in the cortex and medulla tubuli (left panels) (D and E). A scattered pattern of Foxi1-positive cells can be visualized (red arrows). These sections were then subjected to immunohistochemistry using a AQP2-specific Ab (green, right panels). (D and E) Nuclei were stained red with ToPro3. When Foxi1-positive cells (red and blue arrows) are compared with AQP2-positive cells (green), there is no overlap between these two markers. Thus, Foxi1 most likely is expressed in intercalated cells (B and $\mathbf{C}$ ), while principal cells stain negative for Foxi1 (D and E). Scale bars: $10 \mu \mathrm{m}$.

which can be used to distinguish them from intercalated cells (22). To explore whether or not Foxi1 is expressed in principal cells we used Foxi1-specific cRNA probes to identify Foxi1-expressing cells in sections from both cortex and medulla. Such sections were then stained with an AQP2 Ab. This experiment revealed that the staining patterns are not overlapping (Figure 6, D and E). Cells positive for Foxi1 cRNA probes (red arrows, left panels and blue arrows, right panels; Figure 6, D and E) are not positive for AQP2 (green signal, right panels; Figure 6, D and E). In conclusion, the experiments depicted in Figure 6 demonstrate that Foxi1 is expressed in $\alpha$ - and $\beta$-intercalated cells but not in principal cells.

Decreased capacity of Foxi1 $1^{-/}$kidneys to secrete protons. Since gene products of importance for secretion of both protons (e.g., ATP6B1), as well as bicarbonate (e.g., Pds), are missing in the collecting duct epithelium of Foxi1/ $/$ - mice, we set out to investigate the functional properties of this epithelium in vivo. We found that
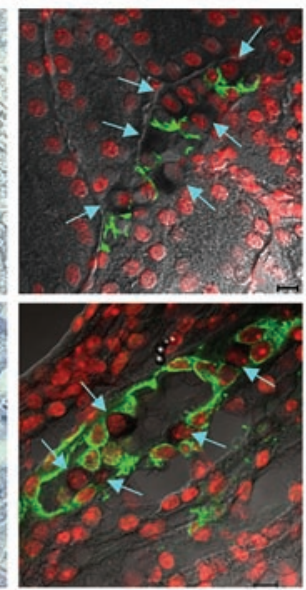

while Foxi1-/- kidneys produced urine with a $\mathrm{pH}$ of $7.49 \pm 0.22$, WT urine had a $\mathrm{pH}$ of $6.46 \pm 0.10$ $(P<0.002 ; n=5)$. We would like to point out that the mouse chow used constitutes a moderate acidic challenge (see Methods). This mild, chronic, acidic load and protons produced by general metabolism are met by acidification of the urine in WT mice, whereas Foxi1 $1^{-/}$mice appear to be compromised in this respect. Plasma potassium concentration was lower in Foxi1 $1 /$ mice $(5.7 \pm 0.58 \mathrm{mM})$ compared with WT mice $(6.8 \pm 0.23 \mathrm{mM} ; P<0.05$; $n=5)$. Low serum levels of potassium are commonly found in dRTA (179800; On-Line Mendelian Inheritance in Man, www.ncbi.nlm.nih. gov). Although not reaching statistical significance, Foxi1 $1 /-$ mice appear to use more of its buffering capacity in response to a moderate chronic acidic load. Base excess values for Foxi1 $1^{-/}$and WT mice were $-8.36 \pm 1.17 \mathrm{mM}$ and $-6.02 \pm 0.36$ $\mathrm{mM}(P=0.07 ; n=5)$, respectively. Taken together, these findings are consistent with a compensated metabolic acidosis in Foxi $1^{-/-}$mice. There were no differences in plasma concentrations of sodium and calcium, diuresis, water intake, or glomerular filtration rate (not shown). To evaluate the capacity of Foxi1 $1^{-/-}$mice to handle a acute acidic load, mice were given a $\mathrm{NH}_{4} \mathrm{Cl}$ solution through a gastric tube (see Methods), essentially as previously described (36). The $\mathrm{pH}$ value was measured in urine samples collected at 4 hours after this challenge. As can be seen in Figure 7A, Foxi1-/- mice are significantly hampered in their ability to respond to an acute acidic load by acidifying their urine $(P<0.02$; $n=4)$. Furthermore, 24 hours after this challenge, Foxi $1^{-/-}$mice were using significantly more of its total buffering capacity, measured as "base excess" (Figure 7B), as compared with WT littermates $(P<0.002 ; n=4)$. This points toward a decreased capacity of eliminating acutely given protons through the urine. Instead, these protons are buffered systemically by consuming a significant amount of the total buffering capacity. When subjected to a prolonged $\mathrm{NH}_{4} \mathrm{Cl}$ load given over a period of 7 days (Methods), Foxi1 ${ }^{-/}$mice developed an overt acidosis. The $\mathrm{pH}$ values in mixed arterial and venous blood were significantly lowered $6.96 \pm 0.04$ $(P<0.01 ; n=5)$ in Foxi1 ${ }^{-/-}$mice and $7.13 \pm 0.04(n=5)$ for WT mice. The $\mathrm{pH}$ value for WT mice did not significantly differ from those in a control group of WT mice that received water only plus the acidic load from the standard diet. Standard bicarbonate lev- 
A

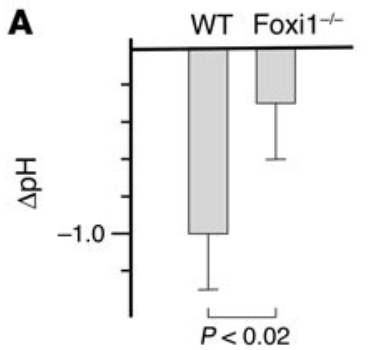

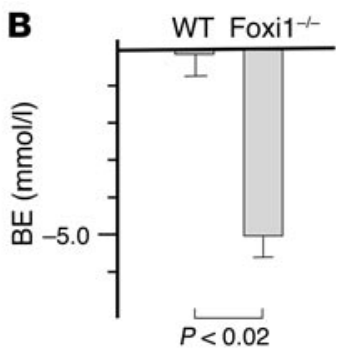

\section{Figure 7}

Response to an acute acidic load (see Methods). WT ( $\mathrm{pH}: 1.01 \pm 0.26)$ mice are capable of acidifying their urine significantly more $(P<0.02, n=5)$ than Foxi1 ${ }^{--}(\mathrm{pH}$ : $0.31 \pm 0.33$ ) mice 4 hours after this challenge $(\mathbf{A})$. Twenty-four hours after this load (B), WT mice had normal base excess values $(-0.08 \pm 1.18)$, whereas Foxi1 $1^{-1-}$ mice had consumed more of their systemic buffering capacity $(-5.00 \pm 0.55 ; P<0.002$, $n=4)$. BE, base excess values. els and base excess were also significantly lower in mice that lack Foxi1 $(P<0.02$ and $P<0.02$, respectively). In Foxi1 $1 /-$ mice standard bicarbonate was $9.78 \pm 0.98 \mathrm{mmol} / \mathrm{l}(n=5)$ and base excess was $-19.76 \pm 1.87 \mathrm{mmol} / \mathrm{l}(n=5)$, while corresponding values for WT mice were $16.62 \pm 1.75 \mathrm{mmol} / \mathrm{l}(n=5)$ and $-8.36 \pm 2.53 \mathrm{mmol} / \mathrm{l}$ $(n=5)$. In WT mice receiving water only plus standard diet, standard bicarbonate levels were $18.45 \pm 1.05 \mathrm{mmol} / \mathrm{l}(n=4)$. This somewhat low value (normal range $23-25 \mathrm{mmol} / \mathrm{l}$ ) is most likely explained by the acidic load derived from the standard chow. Thus, a prolonged challenge of this kind clearly demonstrates a decreased capacity to secrete protons in Foxi1 $1^{-/}$mice, resulting not only in consumption of buffer capacity but also overt acidosis.
The distal nephron epithelium in Foxi1 $1^{-1-}$ mice is made up of a single cell type positive for both intercalated and principal cell markers. The apparent lack of several markers for intercalated cells in Foxi1 $1^{-/-}$mice (e.g., Pds, AE1, AE4, and ATP6B1), taken together with a seemingly normal expression pattern of the principal cell marker AQP2, made us interested in the fate of intercalated cells in null mutants. Are they completely absent, as has been demonstrated for mice that lack CAII (carbanhydrase II; ref. 43) or do they exist as a rudimentary cell population stripped of its expression of many functionally important genes? To address this we set up an experiment in which sections of distal nephron epithelia, both of cortical and medullary origin, from WT and Foxi1-null mutants were stained
A
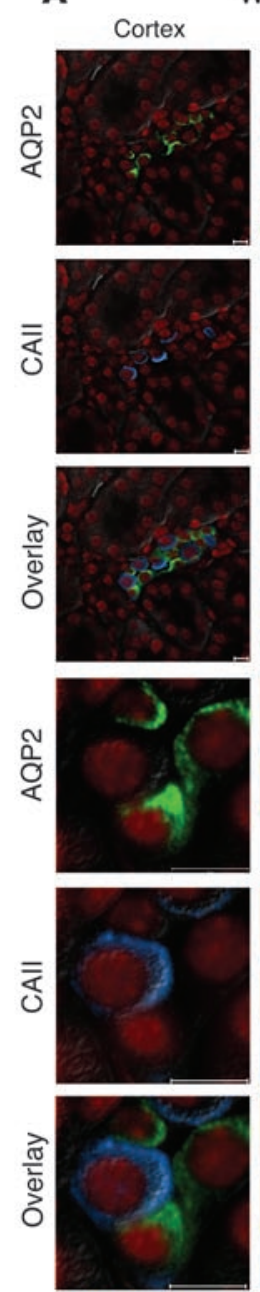

AQP2 CAll TOPrO3
WT
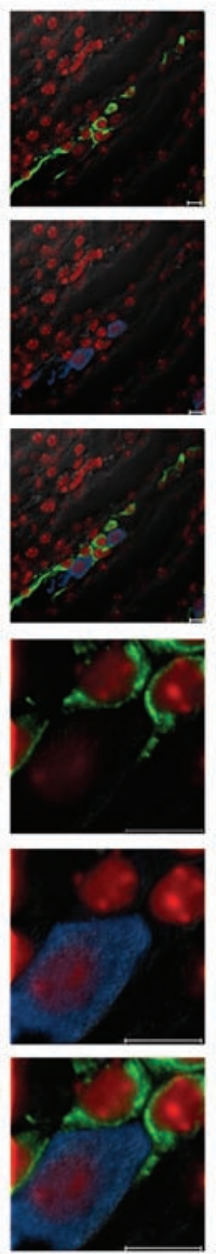

Foxi1 ${ }^{-1-}$
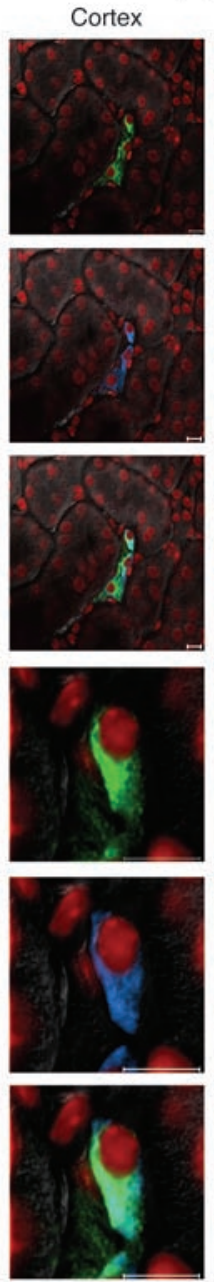

B
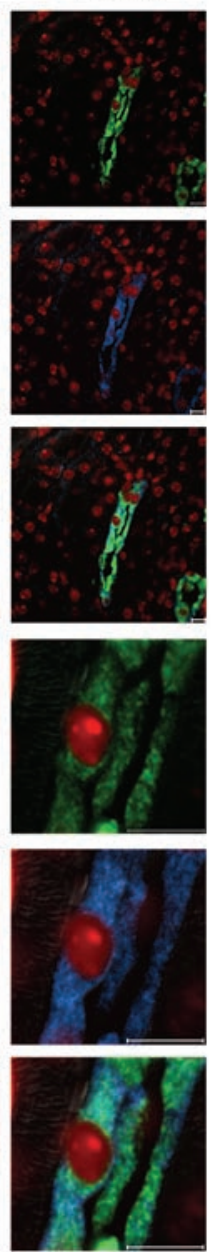

\section{Figure 8}

Cellular distribution of intercalated and principal cell markers. Confocal analysis of sections from cortex and medulla of WT and Foxi1 $1^{-/}$origin (A). Sections were stained using specific antiseras against CAll (intercalated cell marker, blue) and AQP2 (principal cell marker, green); nuclei were stained with ToPro3 (red). When overlays are compared in WT sections, specific subsets of cells stain positive for either CAll (intercalated cells) or AQP2 (principal cells). On the other hand, in Foxi $1^{-1-}$ sections the two signals overlap completely, and one cell population is identified, positive for both markers. While the AQP2 signal in WT sections is localized to the apical aspect of principal cells, the AQP2 signal is more diffuse and generalized in Foxi1 ${ }^{-1}$ epithelia. When relative cell numbers are compared (B), it is obvious that only one cell population positive for both markers exists in Foxi1 $1^{-/-}$epithelia. C, cortex; OM, outer medulla; IM, inner medulla. Scale bars: $10 \mu \mathrm{m}$. 


\section{Embryonic precursor cell}
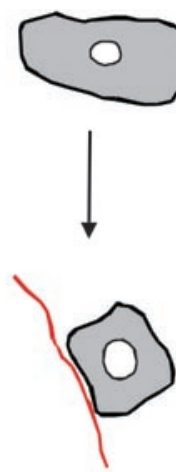

\section{Epithelial precursor cell}

Foxi1-

CAll ${ }^{+}$

AQP2*

Foxi1-regulated step
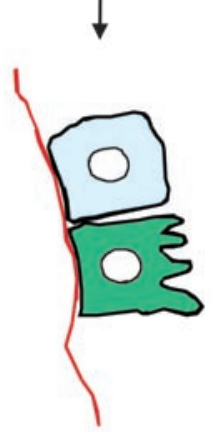

Principal cell

Foxi1-

CAII $^{-}$

AQP2+

Intercalated cell

Foxi1*

$\mathrm{CAll}^{+}$

AQP2-

\section{Figure 9}

A schematic view of a hypothetical differentiation scheme for principal and intercalated cells. Embryonic precursor cells of ureteric bud origin gradually acquire an epithelial phenotype. These cells are positive for both CAII and AQP2. In the next, Foxi1-regulated step, two separate cell populations arise: principal cells (Foxi1- ${ }^{-}, \mathrm{CAll}^{-}, \mathrm{AQP}^{+}$) and intercalated cells (Foxi1 ${ }^{+}, \mathrm{CAll}^{+}, \mathrm{AQP} 2^{-}$).

with Ab's directed against CAII (an intercalated cell marker; refs. 20,21 ) and AQP2 (a principal cell marker; 22, 23). While these markers clearly identified two separate cell populations (i.e., principal and intercalated cells in WT mice), they both stain the same cell type in Foxi1/- epithelium (Figure 8A). Furthermore, when AQP2-positive cells and CAII-positive cells are counted in WT epithelium, we find that approximately one-third of such cells are positive only for CAII (intercalated cells), and the remaining twothirds are positive for AQP2 (principal cells) in cortical collecting ducts (Figure 8B). In sections from inner and outer medulla the number of CAII-positive cells gradually decreases. These findings agree well with what has been published in terms of relative cell numbers $(44,45)$. They also explain why most, if not all, cells in collecting duct epithelium of null mutants seem to stain positive for AQP2 (Figure 4C, right panel). In Foxi1-/- epithelium we find no difference in absolute numbers of AQP2/CAII-positive cells as compared with the number of AQP2- and CAII-positive cells in WT mice (not shown). Thus, Foxi1 expression seems to be necessary for proper patterning of this epithelium.

\section{Discussion}

In the collecting duct epithelium, $\alpha$-intercalated cells express high levels of a vacuolar $\mathrm{H}^{+}$-ATPase, effecting transcellular proton transport at its luminal/apical border. Vacuolar $\mathrm{H}^{+}$-ATPase is part of a machinery present at the apical border of $\alpha$-intercalated cells, consisting of a specialized membrane system inserting and removing proton pumps into the plasma membrane in a way that maintains proper acid-base homeostasis (46). This system also relies on proper polarization and compartmentalization within the epithelial cell. Not surprisingly, absence of protein or mutations in ATP6B1 encoding the $\mathrm{B}_{1}$ subtype unit of the apical $\mathrm{H}^{+}$-ATPase expressed by $\alpha$-intercalated cells of the kidney has been shown to cause dRTA $(15,47)$. Interestingly, such mutations are also associated with sensorineural deafness, indicating that ATP6B1-mediated proton transport is crucial not only for kidney acid-base handling but also for adequate maintenance of the endolymph composition of the inner ear (15). While in Foxi1/- kidneys the steady-state level of ATP6B1 mRNA is similar to that of WT mice (Figure 5), no immunoreactive ATP6B1 protein can be detected in Foxi1 ${ }^{-/}$kidneys (Figure 4, D-G). This might be due to a lack of proper compartmentalization/polarization of the epithelial cells in null mutants. It is conceivable that under such circumstances ATP6B1 is either rapidly degraded or ineffectively translated. Domain-specific proteins (such as ATP6B1) can be removed and degraded during reversal of cell polarity (48), a fact that illustrates how dependent such proteins are on proper epithelial polarity. In Foxi1 $1^{-/}$mice distal nephron epithelial cells seem to lack proper polarity demonstrated by a more generalized pattern of AQP2 staining as compared with WT (Figure 8A). Effective proton secretion in $\alpha$-intercalated cells also requires a simultaneous secretion of bicarbonate through the basolateral membrane. Such activity is carried out by AE1. As can be deduced from Figure 3, D-G, and Figure $5 \mathrm{~A}$, both $A E 1 \mathrm{mRNA}$ and immunodetectable AE1 protein are absent in Foxi1 $1 /$ kidneys. The lack of AE1 mRNA (Figure 5A) and the ability of Foxi1 to induce reporter gene activity from a $k A E 1$ promoter construct in vitro (Figure $5 \mathrm{~B}$ ) makes it likely that Foxi1 is necessary for adequate kAE1 promoter activity in vivo, while the upstream erythrocyte promoter (32) functions well without Foxi1, a fact supported by the presence of immunopositive AE1 in erythrocytes from Foxi1 $1^{-/}$mice (Figure 3, D and E). This establishes Foxi1 as a direct or indirect upstream regulator of kidney AE1 transcription. Lack of the $\alpha$-intercalated marker AE1 (40) expression in Foxi1-/- kidneys also establishes Foxi1 as an important direct or indirect regulator of gene expression in this cell type. Mice lacking Kcc4, a potential Foxi1 target gene, are deaf and show signs of tubular acidosis (16), similar to Foxi1/- mice. Kcc4 mRNA levels in the kidney appear to be unaffected by the absence of Foxi1 expression (Figure 5A), however.

Pendrin is expressed both in the inner ear as well as in $\beta$-intercalated cells $(10,12)$. We used cRNA in situ hybridizations, immunohistochemistry, and Northern blot analysis to investigate Pds expression in Foxi1 ${ }^{-/}$kidneys. As can be seen in Figure 2, E-G, Figure 3, A-C, and Figure 5A, such kidneys lack Pds expression. This is interesting since $\mathrm{Pds}^{-/}$- mice have impaired ability to secrete bicarbonate in vitro (12). Hence, such mice would, if anything, be prone to produce acidic rather than alkalotic urine, the opposite of that found in Foxi1 ${ }^{-/}$mice. The proposed bicarbonate-secreting function of Pds at the apical membrane of the $\beta$-intercalated cell most likely plays only a minor role in total bicarbonate exchange in this cell type. This would explain the very mild, possibly "alkalosisprone" phenotype in $\mathrm{Pds}^{-/-}$mice as well as the overriding acidosis phenotype seen in the Foxi1/- mice that lack ATP6B1 and AE4, as well as Pds and AE1. These findings demonstrate that Foxi1 regulates Pds and AE4 in the kidney, and it also establishes Foxi1 as a direct or indirect regulator of gene expression in $\beta$-intercalated 
cells. In Pds ${ }^{-/}$kidneys AE1 is expressed at the same level as that of WT controls, and immunohistochemistry reveals an expected WTlike basolateral localization of immunoreactive AE1 (not shown). This finding rules out the possibility that AE1 is downregulated in Foxi1 $1^{-/}$kidneys as a consequence of a lack of Pds expression. The seemingly rather modest induction (approximately threefold) of reporter gene activity (Figure 5B) is in accordance with what has been reported for other cases of forkhead-mediated target gene activation, for example, Foxa1 and Foxo1 $(49,50)$.

From the experiments presented here it is evident that lack of Foxi1 leads to dRTA on the basis of a failure to induce proper differentiation of the distal nephron epithelium. Instead of intercalated cells (AQP2-, CAII+) and principal cells (AQP2+, CAII-), a single cell type that is positive for both AQP2 and CAII is found in Foxi1-/- epithelium (Figure 8). This cell type does not express Foxi1 (Figure 2, A-D) nor proteins necessary for proper acid-base handling, for example, Pds, AE1, AE4, and ATP6B1 (Figure 2, E-G, and Figures 3-5). Somewhat speculative, but to a large extent based on the findings presented here and what has been published previously, we would like to propose a model in which the embryonic precursor cells of ureteric bud origin that undergo repetitive dichotomous branching and gradually form the collecting duct system of the metanephric kidney (51), acquire in the next step a gene expression pattern that enables them to maintain basic functions in water and acid-base handling. This is illustrated by the fact that Foxi1-/- mice, unless challenged, have only minor problems with water and acid-base handling, at least in a controlled laboratory environment. We propose that these epithelial precursor cells under normal circumstances constitute a transient cell population characterized by CAII and AQP2 expression with no Foxi1. Activation of Foxi1 is required for these cells to further develop into more specialized cell types. Foxil expression is maintained in the cell population that differentiates into intercalated cells (Foxi1+, CAII+, AQP2-), while principal cells (Foxi1-, CAII-, AQP2+) are derived from progenitors that do not maintain Foxi1 expression (Figure 9). This hypothesis is also supported by the fact that a so called "hybrid" cell - positive for both intercalated and principal cell markers - has been described; approximately $35 \%$ of an in vitro-maintained cell population of collecting duct epithelium was made up of this hybrid cell type (52). Furthermore, the same authors report that this cell type was also found in situ in collecting duct epithelium, albeit at a lower frequency (52), supporting the notion that such precursor cells exist in vivo. We also find that the cortical and outer medulla of WT mice contain a small fraction (less than $3 \%$ ) of collecting duct cells that stain positive for both AQP2 and CAII (Figure 8B). It has also been reported that in primary cultures of collecting duct cells intercalated cells can originate from principal or undifferentiated cells (53). This finding is in agreement with the view of a common progenitor for intercalated and principal cells. The rather late appearance of Foxi1 mRNA in the developing kidney rules out any major effects on early morphogenetic events. The expression in the distal nephron at approximately E16 in mice (7) fits well, however, with a role as a regulator of epithelial patterning in the collecting ducts since, at approximately this stage, the metanephric kidney has well-developed tubuli that just recently connected to the collecting duct system, enabling the first urine to be produced. It is also possible that direct Foxi1-mediated transcriptional activation of $A E 1$ and $P d s$ (Figure 5B) plays an important role in establishing an intercalated cell lineage. Taken together, this information strongly argues in favor of a common progenitor for intercalated and principal cells that, as a response to Foxi1 expression, will give rise to at least two separate cell lineages. Hence, Foxi1 can be regarded as a molecular switch regulating the cellular composition of the distal nephron epithelium.

The role of Foxi1 in the epithelium of the distal nephron is analogous to the situation of FORE cells (9) in inner ear epithelium. Here we would like to point out a striking similarity in cellular morphology between FORE cells of the inner ear and $\alpha$-intercalated cells of the distal nephron $(9,54)$. Finally, the experiments presented here, together with the findings in inner ears that lack Foxi1 expression $(8,9)$, predict that mutations in the human FOXI1 gene, located at $5 \mathrm{q} 34$, might prove to cause a sensorineural deafness syndrome with dRTA.

\section{Acknowledgments}

We thank E.D. Green and L.A. Everett for making a Pds probe, Pds antiserum, and $\mathrm{Pds}^{-/-}$mice available to us. We also thank the following colleagues for making antiserum available to us: D. Brown (ATP6B1), T.J. Jentsch (Kcc4), E. Klussman (AQP2), W.S. Sly (CAII), and the SWEGENE Centers for Bio-Imaging, Cellular Imaging and Mouse Physiology, at Göteborg University, for technical support and assistance. This work was made possible with support from the following: The Swedish Research Council (Grants K2002-99BI14383-01A and K2002-31X-12186-06A to S. Enerbäck and K200204X-03522-31D to E. Persson), EU grants QLK3-CT-2002-02149 and LSHM-CT-2003-503041 (to S. Enerbäck), The Swedish Cancer Society, The Arne and Inga Britt Lundberg Foundation, The Söderberg Foundation, The Wallenberg Foundation, The Swedish Foundation for Strategic Research (Nucleic Acid Program), and The Juvenile Diabetes Research Foundation.

Received for publication December 1, 2003, and accepted in revised form April 6, 2004.

Address correspondence to: Sven Enerbäck, Medical Genetics, Department of Medical Biochemistry, Göteborg University, Medicinareg, 9A, Box 440, SE 40530 Göteborg, Sweden. Phone: 46-317733334; Fax: 46-31-416108; E-mail: sven.enerback@medgen.gu.se.

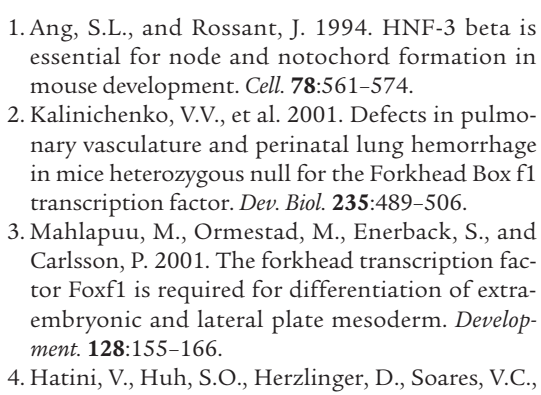

and Lai, E. 1996. Essential role of stromal mesenchyme in kidney morphogenesis revealed by targeted disruption of Winged Helix transcription factor BF-2. Genes Dev. 10:1467-1478.

5. Clevidence, D.E., et al. 1993. Identification of nine tissue-specific transcription factors of the hepatocyte nuclear factor 3/forkhead DNA-binding-domain family. Proc. Natl. Acad. Sci. U. S. A. 90:3948-3952.

6. Pierrou, S., Hellqvist, M., Samuelsson, L., Enerback, S., and Carlsson, P. 1994. Cloning and characterization of seven human forkhead proteins: binding site specificity and DNA bending. EMBO J.
1354:5002-5012.

7. Overdier, D.G., Ye, H., Peterson, R.S., Clevidence, D.E., and Costa, R.H. 1997. The winged helix transcriptional activator HFH-3 is expressed in the distal tubules of embryonic and adult mouse kidney. J. Biol. Chem. 272:13725-13730.

8. Hulander, M., Wurst, W., Carlsson, P., and Enerback, S. 1998. The winged helix transcription factor Fkh10 is required for normal development of the inner ear. Nat. Genet. 20:374-376.

9. Hulander, M., et al. 2003. Lack of pendrin expression leads to deafness and expansion of the endolymphatic compartment in inner ears of Foxi1 null 
mutant mice. Development. 130:2013-2025.

10. Everett, L.A., et al. 2001. Targeted disruption of mouse Pds provides insight about the inner-ear defects encountered in Pendred syndrome. Hum. Mol. Genet. 10:153-161.

11. Everett, L.A., et al. 1997. Pendred syndrome is caused by mutations in a putative sulphate transporter gene (PDS). Nat. Genet. 17:411-422.

12. Royaux, I.E., et al. 2001. Pendrin, encoded by the Pendred syndrome gene, resides in the apical region of renal intercalated cells and mediates bicarbonate secretion. Proc. Natl. Acad. Sci. U. S. A. 98:4221-4226

13. Karet, F.E., et al. 1998. Mutations in the chloridebicarbonate exchanger gene AE1 cause autosomal dominant but not autosomal recessive distal renal tubular acidosis. Proc. Natl. Acad. Sci. U. S. A 95:6337-6342.

14. Batlle, D., Ghanekar, H., Jain, S., and Mitra, A. 2001. Hereditary distal renal tubular acidosis: new understandings. Annu. Rev. Med. 52:471-484.

15. Karet, F.E., et al. 1999. Mutations in the gene encoding B1 subunit of $\mathrm{H}+$-ATPase cause renal tubular acidosis with sensorineural deafness. Nat. Genet. 21:84-90.

16. Boettger, T., et al. 2002. Deafness and renal tubular acidosis in mice lacking the $\mathrm{K}-\mathrm{Cl}$ co-transporter Kcc4. Nature. 416:874-878.

17. Tsuganezawa, H., et al. 2001. A new member of the $\mathrm{HCO} 3(-)$ transporter superfamily is an apical anion exchanger of beta-intercalated cells in the kidney. J. Biol. Chem. 276:8180-8189.

18. Ko, S.B., et al. 2002. AE4 is a DIDS-sensitive $\mathrm{Cl}(-)$ $\mathrm{HCO}(-)(3)$ exchanger in the basolateral membrane of the renal CCD and the SMG duct. Am. J. Physiol. Cell Physiol. 283:C1206-C1218.

19. Alper, S.L., Natale, J., Gluck, S., Lodish, H.F., and Brown, D. 1989. Subtypes of intercalated cells in rat kidney collecting duct defined by antibodies against erythroid band 3 and renal vacuolar $\mathrm{H}^{+-}$ ATPase. Proc. Natl. Acad. Sci. U. S. A. 86:5429-5433.

20. Brown, D., Kumpulainen, T., Roth, J., and Orci, L. 1983. Immunohistochemical localization of carbonic anhydrase in postnatal and adult rat kidney. Am. J. Physiol. 245:F110-F118.

21. Kim, J., Tisher, C.C., Linser, P.J., and Madsen, K.M. 1990. Ultrastructural localization of carbonic anhydrase II in subpopulations of intercalated cells of the rat kidney. J. Am. Soc. Nephrol. 1:245-256.

22. Deen, P.M., et al. 1994. Requirement of human renal water channel aquaporin-2 for vasopressin-dependent concentration of urine. Science. 264:92-95.

23. Fushimi, K., et al. 1993. Cloning and expression of apical membrane water channel of rat kidney collecting tubule. Nature. 361:549-552.

24. Bastani, B. 1997. Immunocytochemical localization of the vacuolar $\mathrm{H}(+)$-ATPase pump in the kidney. Histol. Histopathol. 12:769-779.
25. Bastani, B., Yang, L., and Steinhardt, G. 1994. Immunocytochemical localization of vacuolar $\mathrm{H}$ ATPase in the opossum (Monodelphis domestica) kidney: comparison with the rat.J. Am. Soc. Nephrol. 4:1558-1563

26. Bastani, B., and Haragsim, L. 1996. Immunocytochemistry of renal H-ATPase. Miner. Electrolyte Metab. 22:382-395.

27. Kim, J., Kim, Y.H., Cha, J.H., Tisher, C.C., and Madsen, K.M. 1999. Intercalated cell subtypes in connecting tubule and cortical collecting duct of rat and mouse. J. Am. Soc. Nephrol. 10:1-12.

28. Teng-umnuay, P., Verlander, J.W., Yuan, W., Tisher, C.C., and Madsen, K.M. 1996. Identification of distinct subpopulations of intercalated cells in the mouse collecting duct. J. Am. Soc. Nephrol. 7:260-274.

29. Schwartz, G.J., Barasch, J., and Al-Awqati, Q. 1985. Plasticity of functional epithelial polarity. Nature. 318:368-371

30. Al-Awqati, Q. 2003. Terminal differentiation of intercalated cells: the role of hensin. Annu. Rev. Physiol. 65:567-583.

31. Chomczynski, P., and Sacchi, N. 1987. Single-step method of RNA isolation by acid guanidinium thiocyanate-phenol-chloroform extraction. Anal. Biochem. 162:156-159.

32. Sahr, K.E., Daniels, B.P., and Hanspal, M. 1996. Identification of the proximal erythroid promoter region of the mouse anion exchanger gene. Blood. 88:4500-4509.

33. Bostrom, H., et al. 1996. PDGF-A signaling is critical event in lung alveolar myofibroblast development and alveogenesis. Cell. 85:863-873.

34. Vosshall, L.B., Amrein, H., Morozov, P.S., Rzhetsky, A., and Axel, R. 1999. A spatial map of olfactory receptor expression in the Drosophila antenna. Cell. 96:725-736.

35. Gouraud, S., et al. 2002. Functional involvement of VAMP/synaptobrevin-2 in cAMP-stimulated aquaporin 2 translocation in renal collecting duct cells. J. Cell Sci. 115:3667-3674.

36. Tsuruoka, S., et al. 2003. Nitric oxide production modulates cyclosporin A-induced distal renal tubular acidosis in the rat. J. Pharmacol. Exp. Ther. 305:840-845

37. Wagner, C.A., et al. 2002. Regulation of the expression of the $\mathrm{Cl}$-/anion exchanger pendrin in mouse kidney by acid-base status. Kidney Int. 62:2109-2117.

38. Kaissling, B., and Kriz, W. 1979. Structural analysis of the rabbit kidney. Adv. Anat. Embryol. Cell Biol. 56:1-123.

39. Kim, Y.H., et al. 2002. Immunocytochemical localization of pendrin in intercalated cell subtypes in rat and mouse kidney. Am. J. Physiol. Renal Physiol. 283:F744-F754.

40. Sabolic, I., Brown, D., Gluck, S.L., and Alper, S.L. 1997. Regulation of AE1 anion exchanger and $\mathrm{H}(+)$-ATPase in rat cortex by acute metabolic aci- dosis and alkalosis. Kidney Int. 51:125-137.

41. Brosius, F.C., 3rd, Alper, S.L., Garcia, A.M., and Lodish, H.F. 1989. The major kidney band 3 gene transcript predicts an amino-terminal truncated band 3 polypeptide. J. Biol. Chem. 264:7784-7787.

42. Overdier, D.G., Porcella, A., and Costa, R.H. 1994. The DNA-binding specificity of the hepatocyte nuclear factor 3 /forkhead domain is influenced by amino-acid residues adjacent to the recognition helix. Mol. Cell. Biol. 14:2755-2766.

43. Breton, S., et al. 1995. Depletion of intercalated cells from collecting ducts of carbonic anhydrase II-deficient (CAR2 null) mice. Am. J. Physiol. 269:F761-F774.

44. Hansen, G.P., Tisher, C.C., and Robinson, R.R. 1980. Response of the collecting duct to disturbances of acid-base and potassium balance. Kidney Int. 17:326-337.

45. LeFurgey, A., and Tisher, C.C. 1979. Morphology of rabbit collecting duct. Am. J. Anat. 155:111-124.

46. Nelson, R.D., et al. 1992. Selectively amplified expression of an isoform of the vacuolar $\mathrm{H}(+)$ ATPase 56-kilodalton subunit in renal intercalated cells. Proc. Natl. Acad. Sci. U. S. A. 89:3541-3545.

47. Cohen, E.P., et al. 1992. Absence of H(+)-ATPase in cortical collecting tubules of a patient with Sjogren's syndrome and distal renal tubular acidosis. J. Am. Soc. Nephrol. 3:264-271.

48. Wang, A.Z., Ojakian, G.K., and Nelson, W.J. 1990. Steps in the morphogenesis of a polarized epithelium. II. Disassembly and assembly of plasma membrane domains during reversal of epithelial cell polarity in multicellular epithelial (MDCK) cysts. J. Cell Sci. 95:153-165.

49. Qian, X., Samadani, U., Porcella, A., and Costa, R.H. 1995. Decreased expression of hepatocyte nuclear factor 3 alpha during the acute-phase response influences transthyretin gene transcription. Mol. Cell. Biol. 15:1364-1376.

50. Nakae, J., et al. 2003. The forkhead transcription factor Foxo 1 regulates adipocyte differentiation. Dev. Cell. 4:119-129.

51. Osathanondh, V., and Potter, E.L. 1963. Development of human kidney as shown by microdissection. III. Formation and interrelationship of collecting tubules and nephrons. Arch. Pathol. 76:290-302.

52. Fejes-Toth, G., and Naray-Fejes-Toth, A. 1993. Differentiation of intercalated cells in culture. Pediatr. Nephrol. 7:780-784.

53. Fejes-Toth, G., and Naray-Fejes-Toth, A. 1992. Differentiation of renal beta-intercalated cells to alpha-intercalated and principal cells in culture. Proc. Natl. Acad. Sci. U. S. A. 89:5487-5491.

54. Nicholson, J.K., and Kendall, M.D. 1983. The fine structure of dark or intercalated cells from the distal and collecting tubules of avian kidneys. J. Anat. 136:145-156. 